\title{
Changes of students' understanding in the systemic improvement by dental treatment after undergraduate clinical training in Japan
}

Koji Naruishi ( $\square$ naruishi@tokushima-u.ac.jp )

Tokushima University Graduate School of Biomedical Sciences https://orcid.org/0000-0002-7913-8488

Chie Wada-Mihara

Tokushima University Graduate School of Biomedical Sciences

Keiji Oishi

Tokushima University Graduate School of Biomedicai Sciences

\section{Mika Bando}

Tokushima University Graduate School of Biomedical Sciences

\section{Masami Ninomiya}

Tokushima University Graduate School of Biomedical Sciences

\section{Yuka Hiroshima}

Tokushima University Graduate School of Biomedical Sciences

Jun-ichi Kido

Tokushima University Graduate School of Biomedical Sciences

Tsutomu Iwamoto

Tokushima University Graduate School of Biomedical Sciences

Hiromichi Yumoto

Tokushima University Graduate School of Biomedical Sciences

\section{Research article}

Keywords: dental education, undergraduate clinical training

Posted Date: March 10th, 2020

DOI: https://doi.org/10.21203/rs.3.rs-16609/v1

License: (c) (i) This work is licensed under a Creative Commons Attribution 4.0 International License. Read Full License 


\section{Abstract}

Background: Undergraduate clinical training is a useful program for dental students to learn clinical skills. The aim of this study was to investigate whether dental students who had undergone clinical training understood the clinical significance of dental treatment and its connection to systemic health.

Methods: An awareness survey was conducted in dentistry students both before and after undergraduate clinical training. A total of 42 dental students were recruited before clinical training, and 32 dental students responded to the survey. In addition, all of the 42 dental students responded to the survey after clinical training. A total of 53 medical students were recruited as control subjects. Differences between the 2 groups were analyzed using Fisher's exact test.

Results: Before clinical training, the percentage of dental students who recognized that periodontal treatment has positive effects on systemic diseases was higher than that of the control. After clinical training, a higher percentage of dental students recognized the positive effects of periodontal treatment on systemic health. A higher percentage of dental students before clinical training recognized the positive effects of prosthetic treatment on geriatric conditions; however, after clinical training no significant differences were found between the dental students and the control when surveyed about the positive effects of periodontal and prosthetic treatment on geriatric conditions.

Conclusion: Undergraduate clinical training is useful for improving the students' understanding of the clinical significance of dental treatment. The results of these surveys suggest that dental education supported by experience contributes to an appreciation of the role of dental treatment.

\section{Background}

Marked progress in dental treatment has been made worldwide, and the level of dental education for students has steadily risen. Research has contributed to an improvement in the educational standards not only in the dental field but also in the medical field. Periodontal disease has a negative influence on systemic diseases such as diabetes mellitus, rheumatoid arthritis, and arteriosclerosis $[1,2]$. In addition, the occurrence of aspiration pneumonia is exacerbated by "oral frailty" such as swallowing disorders and poor oral hygiene in older adults [3]. An unclosed mouth and impaired tongue movements, which are related to the strength of the oral muscles, are also associated with a higher incidence of aspiration pneumonia [4]. Age-dependent impaired and vulnerable oral functions caused by tooth loss or unused dentures result in oral frailty. Stable occlusion is an important factor in the prevention of oral frailty. Therefore, prosthetic treatment is an effective indirect treatment for preventing the occurrence of aspiration pneumonia in older adults.

Periodontal disease is an infectious disease that results in the loss of teeth by inflammation-induced alveolar bone resorption [5]. Loss of posterior occlusion is an unwanted consequence of periodontitis progression, and impairment of the masticatory muscles may gradually occur in older people without dentures [6]. In these elderly patients, oral pathogens readily lodge into their bronchial tubes, which leads to the development of aspiration pneumonia. In addition, periodontal treatment prevents tooth loss and enables the consumption of more enjoyable meals, which supports overall nutrition [7]. Therefore, both periodontal and prosthetic treatments have, directly and indirectly, positive effects on the prevention of aspiration pneumonia. Dental students should be taught that periodontal treatment is essential not only for the improvement of systemic diseases, such as diabetes mellitus in middle-aged people, but also the stability of posterior occlusions for the prevention of aspiration pneumonia in elderly people. Ultimately, the therapeutic goal of periodontal treatment is to contribute to the systemic health of people in different age groups.

In Japan, dental students learn basic medical and dental science during the first 4 years of their undergraduate curriculum. The first encounter with patients during undergraduate clinical training is a key part of the undergraduate 
program in dental universities in Japan. The students learn to prevent, diagnose and treat various oral diseases such as periodontitis, and tooth loss. However, it is necessary to evaluate whether, after completion of clinical training, dental students have fully understood the clinical significance of dental treatment for the systemic health of patients of different ages and whether the role of periodontal and prosthetic treatment for systemic improvement is fully recognized. In the present study, we evaluated the educational effectiveness of undergraduate clinical training in dental school.

\section{Methods}

\section{Undergraduate clinical training}

In general, there are 2 main teaching/learning methods: traditional lectures and clinical training in the undergraduate educational curriculum of dentistry. Traditionally, lectures involve demonstration by a teacher/instructor in front of the classroom. This is often termed "teacher-centered education", because the students are expected to sit and listen. On the other hand, clinical training after a lecture course is student-centered. During their undergraduate clinical training courses, dental students are supervised by professionals, and actively involved in the treatment of patients. Clinical training is a useful program for elevating the clinical skills of dental students, contributing to deepening their knowledge of the topics studied in their lectures, heightening their sense of both responsibility and cooperation, and developing their clinical thinking.

The 5-6th year dental students see patients for 1 year at the student clinic of our university hospital. They have firsthand experience of the dental care from the medical interview at first visit to the maintenance phase after treatment under the guidance of seasoned instructors for procedures such as simple tooth extraction, basic periodontal treatment, and prosthetic treatment.

\section{Subjects and awareness survey}

An awareness survey of dental students before and after clinical training at Tokushima University Hospital for the effects of periodontal or prosthetic treatment on diseases, symptoms, and conditions was performed during the 201819 academic year. A total of 42 dental students (male: 27, female: 15) before clinical training were recruited, and 32 dental students (male: 22, female: 10) responded to the survey. In addition, all of the 42 dental students responded to the survey after completion of clinical training. As control subjects, a total of 55 Tokushima University medical students (4th-year students before clinical training) were recruited, and 53 medical students (male: 25, female: 28) responded to the survey. The medical students had not received any lectures about dental treatment.

A written informed consent form was signed by every student involved in this study. The questionnaire was anonymous, and students were allowed to decline or withdraw from participation at any time without any negative consequences. This study was approved by the ethics committee of Tokushima University Hospital (No. 3454).

\section{Statistical analysis}

The results of this questionnaire were tallied immediately, and the outcomes were calculated as percentages of the available responses. The results were analyzed by Fisher's exact test. Statistical analyses were performed using JMP ${ }^{\circledR} 8$ ver. 8.0.2 (SAS Institute Japan, Tokyo). P-values of $<0.05$ were considered significant.

\section{Results}




\section{Comparison of the awareness survey results between dental and medical students before clinical training for the effects of dental treatment on systemic health}

To examine whether there were significant differences about recognizing the positive effects of dental treatment on systemic conditions between the dental and medical students before undergraduate clinical training, we conducted an awareness survey (Table 1). The percentage of dental students who recognized that periodontal treatment has positive effects on systemic diseases (diabetes mellitus: $P=0.013$, arteriosclerosis: $P=0.0007$, cerebrovascular disorder: $P=0.013$, aspiration pneumonia: $\mathrm{P}=0.020$ ) was higher than that of the medical students. On the other hand, no significant differences were found between the dental and medical students in the recognition of the effects of periodontal treatment on oral-, geriatric-, and feelings-of-happiness-related factors. There were no significant differences between the dental and medical students in almost all of the survey items concerning the effects of prosthetic treatment; however, the percentage of medical students who recognized that prosthetic treatment has a positive effect on halitosis $(P=0.044)$ was higher than that of dental students.

\section{Comparison before and after clinical training of the dental students' recognition of the effects of periodontal or prosthetic treatment on systemic health}

To examine whether there were significant differences between the students' recognition of the positive effects of dental treatment on several systemic conditions before and after clinical training, we conducted another awareness survey (Table 2). A higher percentage of dental students recognized the positive effects of periodontal treatment on systemic diseases after clinical training (diabetes mellitus: $\mathrm{P}=0.017$, pustulosis palmoplantaris: $\mathrm{P}=0.047$, aspiration pneumonia: $P=0.039)$. The students also recognized the positive effects of both periodontal and prosthetic treatment on geriatric conditions (periodontal, nutritional function: $P=0.0006$, cognitive function: $P=0.0001$; prosthetic, nutritional function: $\mathrm{P}=0.008$, cognitive function: $\mathrm{P}=0.003$ ). There were no significant differences before and after clinical training in the students' recognition of the effects of prosthetic treatment on systemic diseases (diabetes mellitus, $\mathrm{P}=0.06$, pustulosis palmoplantaris, $P=0.69)$. A significant difference was found in the students' recognition of the effect of prosthetic treatment on aspiration pneumonia $(P=0.0005)$.

\section{Comparison of the ability of students to choose the most effective treatment between periodontal and prosthetic treatment and their effects on systemic health}

To examine whether there are significant differences in the ability of students to choose the most effective treatment between periodontal and prosthetic treatment and the students' recognizing the positive effects of treatment on systemic health, we analyzed the results of an awareness survey before and after clinical training (Table 3 ). Before clinical training, the dental students recognized that periodontal treatment is important for preventing various systemic diseases such as diabetes mellitus $(P=0.018)$, arteriosclerosis $(P<0.0001)$, rheumatoid arthritis $(P=0.028)$, and chronic kidney disease $(P=0.0008)$, compared with prosthetic treatment. Conversely before clinical training, the students recognized that prosthetic treatment is more important for improving geriatric conditions, such as swallowing disorders $(P=0.042)$, walking function $(P=0.001)$, nutritional condition $(P=0.002)$, and cognitive function $(P=0.019)$, compared with periodontal treatment. Furthermore, most dental students before clinical training recognized that there are positive effects on the quality of life or healthy life expectancy which are related to both periodontal and prosthetic treatment; however, no significant difference was found.

Next, we surveyed the same subjects after completion of clinical training to evaluate the effects of their education. The dental students after clinical training still recognized that periodontal treatment is more important for preventing systemic diseases, such as diabetes mellitus $(P=0.0009)$, arteriosclerosis $(P=0.006)$, rheumatoid arthritis $(P=0.005)$, and chronic kidney disease $(P=0.004)$, compared with prosthetic treatment. No significant difference was found in the 
students' recognition of the role of periodontal treatment in preventing pustulosis palmoplantaris, even after clinical training. Importantly, in the survey concerning geriatric conditions, no significant difference between the students' recognition of the role of periodontal and prosthetic treatment was found after clinical training. Most dental students after clinical training recognized that there are positive effects on geriatric conditions not only as a result of prosthetic treatment but also periodontal treatment.

\section{Discussion}

Dental patients with systemic diseases that require an accurate knowledge of pathogenesis have been increasing $[8,9]$. In order to diagnose and treat these patients correctly, dentists need to be familiar with cardiovascular, respiratory, immune, endocrine, metabolic diseases, etc. Iwamoto et al. reported previously that $\mathrm{HbA} 1 \mathrm{c}$ levels were reduced significantly in periodontitis patients with diabetes after anti-microbial periodontal treatment [10]. In addition, prosthetic treatment increases food intake, resulting in an improvement of nutritional status [11,12]. It is generally accepted that dental treatment can contribute to an improvement not only in oral conditions but also in feelings of happiness in dental patients $[13,14]$. The benefits of dental treatment must be communicated effectively to dental students. Therefore, we evaluated whether the undergraduate students at dental school understood the significance of periodontal and prosthetic treatment in the systemic health of patients.

First, we examined the educational effects of traditional lectures on the dental students' understanding of the positive relationship between systemic health and dental treatment, such as periodontal and prosthetic treatment, using an awareness survey before clinical training. As a control, we surveyed medical students before clinical training, because the medical students had not received any lectures about dental treatment. The survey evaluated whether the students recognized the significance of dental treatment for the systemic health of patients after traditional lectures. As expected, most dental students recognized the effects of periodontal treatment on several systemic diseases compared with the medical students (Table 1), one of the most important topics in the field [1,2]. Traditional lectures before clinical training are useful to help students recognize the importance of periodontal treatment on systemic improvement. In addition, there were no significant differences between dental and medical students in the recognition of the effects of periodontal treatment on geriatric- and feelings-of-happiness-related factors. Unfortunately, the systemic effects of tooth loss due to the progression of periodontitis were not fully recognized, even in dental students after their lectures. Interestingly, no significant differences were observed between dental and medical students in the recognition of the positive effects of prosthetic treatment on systemic health. Both dental and medical students may feel that prosthetic treatment is only essential for the improvement of mastication while eating. Surprisingly, more medical students recognized that there is a positive effect of prosthetic treatment on the improvement of halitosis symptoms. Most medical students recognized that prosthetic treatment is same as full-denture wearing, and that halitosis may be improved by completely washing the dentures using a cleaner.

Next, to examine whether undergraduate clinical training deepens the students' understanding about the clinical significance of dental treatment to systemic health, the same subjects were surveyed after completion of clinical training (Table 2). Although dental students before clinical training understood that periodontal treatment improves the outcomes of systemic diseases, such as diabetes mellitus and aspiration pneumonia, after clinical training the students had a deeper understanding of the topic. In addition, a significantly higher percentage of students recognized the positive effects of prosthetic treatment on aspiration pneumonia after clinical training, despite not understanding the effects before clinical training. These results indicate that the students learned the relationship between aspiration pneumonia and periodontitis in the lectures on periodontics, but not the lectures on prosthetics. Although aspiration pneumonia is a systemic disease, the disease is also considered a geriatric disease which may explain our findings. 
Currently, Japan has an aging population [15]. Our previous findings showed that the progression of oral frailty symptoms, such as an unclosed mouth, impaired tongue movements, and loss of posterior occlusion, is a significant risk factor associated with aspiration pneumonia in elderly patients, which decreases the quality of life [4]. Loss of posterior occlusion is an unexpected consequence of periodontitis, therefore periodontal treatment must be performed in middle-aged people to prevent tooth loss so that the quality of life is not affected. The ultimate objective of periodontal treatment in middle-aged people is to improve their quality of life as they age. Geriatric conditions, such as tooth loss, may be improved by prosthetic treatment, e.g. denture wearing in elderly people. The importance of periodontal treatment should be emphasized in order to promote the health of elderly patients in the future and this should be taught in the periodontics curriculum. As shown in Table 2, dental students after clinical training fully recognized the improvement of several geriatric factors, even such factors as walking function or cognitive function, which are connected to not only prosthetic treatment but also periodontal treatment. Both periodontal and prosthetic treatment contribute to the prevention of geriatric impairment, resulting in an improvement of the patients' quality of life. An effective curriculum should be designed to enable dental students to recognize the importance of dental treatment.

Finally, we considered the following question: "Which is superior, periodontal or prosthetic treatment, for the improvement of systemic health?" As expected, most dental students both before and after clinical training recognized that periodontal treatment has more positive effects than prosthetic treatment in the improvement of systemic diseases such as diabetes, arteriosclerosis, rheumatoid arthritis, and chronic kidney disease (Table 3). On the other hand, although most dental students before clinical training recognized that prosthetic treatment has more positive effects than periodontal treatment in the improvement of geriatric factors, such as swallowing function, nutritional condition, and walking function, there were no significant differences regarding the recognition of periodontal and prosthetic treatments in the improvement of all geriatric factors after the completion of clinical training. This recognition could be improved by undergraduate clinical training that includes explanations of how both periodontal and prosthetic treatment contribute to improving the condition of geriatric patients. Furthermore, we propose the necessity of collaboration with a dentist in geriatric field, although the recognition of students was not surveyed in this study. We expect necessity of the multi-disciplinary approach should be educated to the dental students at first, and the common understanding in dental field will expand to the medical field in the future.

There is a saying in the United Kingdom: "Experience without learning is better than learning without experience." We propose that a combination of experience gained by clinical training and evidence obtained from traditional lectures should underlie the experience- and evidence-based education (EEBE) model that is used in dentistry education. We believe that EEBE is the most important concept for creating the foundation of the dental educational program used at our school. The idea that the ultimate objective of both periodontal and prosthetic treatment is to improve the quality of life of patients as they age should be conveyed to all dental students.

\section{Conclusions}

Both traditional lectures and clinical training help students learn in different ways. Undergraduate clinical training is more effective for increasing the students' understanding of the clinical significance of dental treatment for systemic health. Our survey suggests that an educational program of evidence-based medicine supported by EEBE contributes to understanding the clinical significance of dental treatment for systemic health.

\section{Declarations}

Acknowledgements: The authors thank the staff of Tokushima University for their assistance. 


\section{Author's contributions}

$\mathrm{KN}$ contributed to conception and design, data analyses, interpretation of the results and preparation of manuscript. $\mathrm{CM}, \mathrm{KO}, \mathrm{MB}, \mathrm{MN}, \mathrm{YH}, \mathrm{JK}, \mathrm{TI}$ and $\mathrm{HY}$ revised critically the manuscript. All authors approved the final version of the manuscript.

\section{Funding}

This study was supported by a Grant-in-Aid for Scientific Research (C) (No. 19K10131) from the Japan Society for the Promotion of Science.

\section{Ethics approval and consent to participate}

This study was approved by the ethics committee of Tokushima University Hospital (No. 3454).

\section{Consent for publication}

None.

\section{Competing interests}

The authors of this paper have no interests to declare.

\section{References}

1. Moutsopoulos NM, Madianos PN. Low-grade inflammation in chronic infectious diseases: paradigm of periodontal infections. Ann NY Acad Sci. 2006;1088:251-64.

2. Sabharwal A, Gomes-Filho IS, Stellrecht E, Scannapieco FA. Role of periodontal therapy in management of common complex systemic diseases and conditions: An update. Periodontol 2000. 2018;78:212-6.

3. van der Maarel-Wierink CD, Vanobbergen JN, Bronkhorst EM, Schols JM, de Baat C. Oral health care and aspiration pneumonia in frail older people: a systematic literature review. Gerodontology. 2013;30:3-9.

4. Naruishi K, Nishikawa Y, Kido J, Fukunaga A, Nagata T. Relationship of aspiration pneumonia to cognitive impairment and oral condition: a cross-sectional study. Clin Oral Investig. 2018;22:2575-80.

5. Armitage GC. Clinical evaluation of periodontal diseases. Periodontol 2000. 1995;7:39-53.

6. Naruishi K, Kunita A, Kubo K, Nagata T, Takashiba S, Adachi S. Predictors of improved functional outcome in elderly inpatients after rehabilitation: a retrospective study. Clin Interv Aging. 2014;9:2133-41.

7. Scannapieco FA, Cantos A. Oral inflammation and infection, and chronic medical diseases: implications for the elderly. Periodontol 2000. 2016;72:153-75.

8. Monteserín-Matesanz M, Esparza-Gómez GC, García-Chías B, Gasco-García C, Cerero-Lapiedra R. Descriptive study of the patients treated at the clinic "integrated dentistry for patients with special needs" at Complutense University of Madrid (2003-2012). Med Oral Patol Oral Cir Bucal. 2015;20:e211-7.

9. Lamster IB. Geriatric periodontology: how the need to care for the aging population can influence the future of the dental profession. Periodontol 2000. 2016;72:7-12.

10. Iwamoto Y, Nishimura F, Nakagawa M, Sugimoto H, Shikata K, Makino H, et al. The effect of antimicrobial periodontal treatment on circulating tumor necrosis factor-alpha and glycated hemoglobin level in patients with type 2 diabetes. J Periodontol. 2011;72:774-8. 
11. Prakash N, Kalavathy N, Sridevi J, Premnath K. Nutritional status assessment in complete denture wearers. Gerodontology. 2012;29:224-30.

12. Amagai N, Komagamine $\mathrm{Y}$, Kanazawa M, Iwaki M, Jo A, Suzuki H, et al. The effect of prosthetic rehabilitation and simple dietary counseling on food intake and oral health related quality of life among the edentulous individuals: A randomized controlled trial. J Dent. 2017;65:89-94.

13. Murai O, Sasaki D, Ando Y, Fujimura A, Oikawa $H$, Suwa N, et al. Improvement of pustulosis palmaris et plantaris by periodontal infection control in a patient with chronic periodontitis. Clin Lab. 2012;58:323-7.

14. Madianos PN, Koromantzos PA. An update of the evidence on the potential impact of periodontal therapy on diabetes outcomes. J Clin Periodontol. 2018;45:188-95.

15. Kojima T, Mizukami K, Tomita N, Arai H, Ohrui T, Eto M, et al. Screening tool for older persons' appropriate prescriptions for Japanese: Report of the Japan Geriatrics Society Working Group on "Guidelines for medical treatment and its safety in the elderly", Geriatr Gerontol Int. 2016;16:983-1001.

\section{Tables}

Table 1. An awareness survey of dental and medical students before clinical training about the effects of periodontal or prosthetic treatment on diseases, symptoms, and conditions

\begin{tabular}{|c|c|c|c|c|c|c|}
\hline \multirow[t]{3}{*}{ Survey item } & \multicolumn{6}{|c|}{ Considered positive effects (\%) } \\
\hline & \multicolumn{3}{|c|}{ Periodontal treatment } & \multicolumn{3}{|c|}{ Prosthetic treatment } \\
\hline & $\begin{array}{c}\text { Dental } \\
\text { students } \\
(\mathrm{N}=32)\end{array}$ & $\begin{array}{c}\text { Medical } \\
\text { students } \\
(\mathrm{N}=53)\end{array}$ & $\mathrm{P}$-value & $\begin{array}{c}\text { Dental } \\
\text { students } \\
(\mathrm{N}=32)\end{array}$ & $\begin{array}{l}\text { Medical } \\
\text { students } \\
(\mathrm{N}=53)\end{array}$ & P-value \\
\hline \multicolumn{7}{|l|}{ Oral: } \\
\hline Not extracted & 100 & 94.3 & 0.17 & 75.0 & 83.0 & 0.37 \\
\hline Halitosis & 68.8 & 83.0 & 0.13 & 43.8 & 66.0 & $0.044^{*}$ \\
\hline \multicolumn{7}{|l|}{ Systemic diseases: } \\
\hline Obesity & 65.6 & 43.4 & 0.088 & 53.1 & 58.5 & 0.63 \\
\hline Diabetes mellitus & 81.3 & 54.7 & $0.013 *$ & 50.0 & 49.1 & 0.93 \\
\hline Stomach cancer & 56.3 & 60.4 & 0.71 & 46.9 & 45.3 & 0.89 \\
\hline Arteriosclerosis & 71.9 & 34.0 & $0.0007 * *$ & 43.8 & 35.9 & 0.47 \\
\hline $\begin{array}{l}\text { Cerebrovascular } \\
\text { disorder }\end{array}$ & 65.6 & 37.7 & $0.013 *$ & 43.8 & 34.0 & 0.37 \\
\hline Pustulosis & 25.0 & 32.1 & 0.49 & 31.3 & 22.6 & 0.38 \\
\hline \multicolumn{7}{|l|}{ palmoplantaris } \\
\hline Arthritis rheumatoid & 56.3 & 35.9 & 0.066 & 37.5 & 32.1 & 0.61 \\
\hline Chronic kidney disease & 43.8 & 32.1 & 0.28 & 37.5 & 34.0 & 0.74 \\
\hline $\begin{array}{l}\text { Nonalcoholic } \\
\text { steatohepatitis }\end{array}$ & 37.5 & 20.8 & 0.092 & 34.4 & 26.4 & 0.44 \\
\hline Aspiration pneumonia & 84.4 & 60.4 & $0.020 *$ & 59.4 & 64.2 & 0.66 \\
\hline \multicolumn{7}{|l|}{ Geriatric: } \\
\hline Eating/Swallowing & 75.0 & 69.8 & 0.61 & 87.5 & 81.1 & 0.24 \\
\hline \multicolumn{7}{|l|}{ function } \\
\hline Eating function & 87.7 & 79.3 & 0.33 & 93.8 & 86.8 & 0.31 \\
\hline Swallowing function & 78.1 & 71.7 & 0.51 & 93.8 & 83.0 & 0.15 \\
\hline Walking function & 43.8 & 35.9 & 0.47 & 50.0 & 43.4 & 0.55 \\
\hline Nutritional condition & 75.0 & 77.4 & 0.80 & 84.4 & 81.1 & 0.70 \\
\hline Cognitive function & 62.5 & 56.6 & 0.59 & 81.3 & 66.0 & 0.13 \\
\hline \multicolumn{7}{|l|}{ Feelings of happiness: } \\
\hline Quality of life & 84.4 & 84.9 & 0.95 & 90.6 & 84.9 & 0.45 \\
\hline Healthy life expectancy & 90.6 & 84.9 & 0.45 & 84.4 & 83.0 & 0.87 \\
\hline
\end{tabular}

An awareness survey of dental and medical students before clinical training was performed. A total of 42 dental students were recruited, and 32 dental students responded to the survey. A total of 55 medical students were recruited, and 53 medical students responded to the survey. Dental students consisted of those who had taken both the periodontics and prosthodontics lectures. Medical students had not taken a dentistry lecture. Significant differences between the dental and medical students were examined using Fisher's exact test. *, $\mathrm{P}<0.05$; **, $\mathrm{P}<0.01$. The boldface indicates the "significantly higher" results. 
Table 2. Changes in awareness of dental students after clinical training about the effects of periodontal or prosthetic treatment on diseases, symptoms, and conditions

\begin{tabular}{|c|c|c|c|c|c|c|}
\hline \multirow[t]{3}{*}{ Survey item } & \multicolumn{6}{|c|}{ Considered positive effects (\%) } \\
\hline & \multicolumn{3}{|c|}{ Periodontal treatment } & \multicolumn{3}{|c|}{$\begin{array}{l}\text { Prosthetic treatment } \\
\end{array}$} \\
\hline & $\begin{array}{c}\text { Before clinical } \\
\text { training }(\mathrm{N}=32)\end{array}$ & $\begin{array}{c}\text { After clinical } \\
\text { training }(\mathrm{N}=42)\end{array}$ & P-value & $\begin{array}{l}\text { Before clinical } \\
\text { training }(\mathrm{N}=32)\end{array}$ & $\begin{array}{c}\text { After clinical } \\
\text { training }(\mathrm{N}=42)\end{array}$ & P-value \\
\hline \multicolumn{7}{|l|}{ Oral: } \\
\hline Not extracted & 100 & 100 & $\mathrm{NE}$ & 75.0 & 100 & $0.0006 * *$ \\
\hline Halitosis & 68.8 & 100 & $0.0001 * *$ & 43.8 & 73.8 & $0.009 * *$ \\
\hline \multicolumn{7}{|l|}{ Systemic diseases: } \\
\hline Obesity & 62.5 & 78.6 & 0.13 & 53.1 & 69.0 & 0.16 \\
\hline Diabetes mellitus & 81.3 & 97.6 & $0.017 *$ & 50.0 & 71.4 & 0.06 \\
\hline Stomach cancer & 56.3 & 54.8 & 0.90 & 46.9 & 40.5 & 0.58 \\
\hline Arteriosclerosis & 71.9 & 81.0 & 0.36 & 43.8 & 52.4 & 0.46 \\
\hline $\begin{array}{l}\text { Cerebrovascular } \\
\text { disorder }\end{array}$ & 65.6 & 76.2 & 0.32 & 43.8 & 52.4 & 0.46 \\
\hline $\begin{array}{l}\text { Pustulosis } \\
\text { palmoplantaris }\end{array}$ & 25.0 & 47.6 & $0.047 *$ & 31.3 & 35.7 & 0.69 \\
\hline Arthritis & 56.3 & 69.0 & 0.26 & 37.5 & 38.1 & 0.96 \\
\hline $\begin{array}{l}\text { rheumatoid } \\
\text { Chronic kidney } \\
\text { disease }\end{array}$ & 43.8 & 59.5 & 0.18 & 37.5 & 28.6 & 0.42 \\
\hline $\begin{array}{l}\text { Nonalcoholic } \\
\text { steatohepatitis }\end{array}$ & 37.5 & 47.6 & 0.38 & 34.4 & 28.6 & 0.59 \\
\hline $\begin{array}{l}\text { Aspiration } \\
\text { pneumonia }\end{array}$ & 84.4 & 97.6 & $0.039 *$ & 59.4 & 92.9 & $0.0005^{* *}$ \\
\hline $\begin{array}{l}\text { Geriatric: } \\
\text { Eating/Swallowing }\end{array}$ & 75.0 & 95.2 & $0.011 *$ & 87.5 & 95.2 & 0.43 \\
\hline $\begin{array}{l}\text { function } \\
\text { Eating function }\end{array}$ & & & & & & \\
\hline Eating function & 87.7 & 97.6 & 0.086 & 93.8 & 95.2 & 0.78 \\
\hline $\begin{array}{l}\text { Swallowing } \\
\text { function }\end{array}$ & 78.1 & 95.2 & $0.026^{*}$ & 93.8 & 95.2 & 0.78 \\
\hline Walking function & 43.8 & 69.0 & $0.029 *$ & 50.0 & 78.6 & $0.01 *$ \\
\hline $\begin{array}{l}\text { Nutritional } \\
\text { condition }\end{array}$ & 75.0 & 100 & $0.0006 * *$ & 84.4 & 100 & $0.008 * *$ \\
\hline Cognitive function & 62.5 & 97.6 & $0.0001 * *$ & 81.3 & 100 & $0.003 * *$ \\
\hline Feelings $\quad$ of & & & & & & \\
\hline $\begin{array}{l}\text { happiness: } \\
\text { Quality of life }\end{array}$ & 84.4 & 100 & $0.008^{* *}$ & 90.6 & 100 & $0.043^{*}$ \\
\hline $\begin{array}{l}\text { Healthy } \\
\text { expectancy }\end{array}$ & 90.6 & 100 & $0.043^{*}$ & 84.4 & 97.6 & 0.039* \\
\hline
\end{tabular}

An awareness survey of dental students before and after clinical training was performed. A total of 42 dental students were recruited before clinical training, and 32 dental students responded to the survey. A total of 42 dental students were recruited after clinical training, and 42 dental students responded to the survey. Significant differences before and after clinical training were examined using Fisher's exact test. *, $\mathrm{P}<0.05$; **, $\mathrm{P}<0.01$. NE, not examined. The boldface indicates the "significantly higher" results.

Table 3. Comparison of awareness of the best course of treatment between periodontal and prosthetic treatment and the student's recognition about the effect on diseases, symptoms, and conditions 


\begin{tabular}{|c|c|c|c|c|c|c|}
\hline \multirow[t]{3}{*}{ Survey item } & \multicolumn{6}{|c|}{ Considered positive effects (\%) } \\
\hline & \multicolumn{3}{|c|}{ Before clinical training $(\mathrm{N}=32)$} & \multicolumn{3}{|c|}{ After clinical training $(\mathrm{N}=42)$} \\
\hline & $\begin{array}{c}\text { Periodontal } \\
\text { treatment }\end{array}$ & $\begin{array}{l}\text { Prosthetic } \\
\text { treatment }\end{array}$ & P-value & $\begin{array}{l}\text { Periodontal } \\
\text { treatment }\end{array}$ & $\begin{array}{l}\text { Prosthetic } \\
\text { treatment }\end{array}$ & P-value \\
\hline \multicolumn{7}{|l|}{ Oral: } \\
\hline Not extracted & 100 & 75.0 & $0.003 * *$ & 100 & 100 & $\mathrm{NE}$ \\
\hline Halitosis & 68.8 & 43.8 & 0.45 & 100 & 73.8 & $0.0004 * *$ \\
\hline \multicolumn{7}{|l|}{ Systemic diseases: } \\
\hline Obesity & 65.6 & 53.1 & $0.008 * *$ & 78.6 & 69.0 & 0.32 \\
\hline Diabetes mellitus & 81.3 & 50.0 & $0.018 *$ & 97.6 & 71.4 & $0.0009 * *$ \\
\hline Stomach cancer & 56.3 & 46.9 & $<0.0001^{* *}$ & 54.8 & 40.5 & 0.19 \\
\hline Arteriosclerosis & 71.9 & 43.8 & $0.002^{* *}$ & 81.0 & 52.4 & $0.006 * *$ \\
\hline $\begin{array}{l}\text { Cerebrovascular } \\
\text { disorder }\end{array}$ & 65.6 & 43.8 & 0.061 & 76.2 & 52.4 & $0.023 *$ \\
\hline $\begin{array}{l}\text { Pustulosis } \\
\text { palmoplantaris }\end{array}$ & 25.0 & 31.3 & 0.072 & 47.6 & 35.7 & 0.27 \\
\hline $\begin{array}{l}\text { Arthritis } \\
\text { rheumatoid }\end{array}$ & 56.3 & 37.5 & $0.028 *$ & 69.0 & 38.1 & $0.005^{* *}$ \\
\hline $\begin{array}{l}\text { Chronic kidney } \\
\text { disease }\end{array}$ & 43.8 & 37.5 & $0.0008 * *$ & 59.5 & 28.6 & $0.004^{* *}$ \\
\hline $\begin{array}{l}\text { Nonalcoholic } \\
\text { steatohepatitis }\end{array}$ & 37.5 & 34.4 & $0.006^{* *}$ & 47.6 & 28.6 & 0.072 \\
\hline $\begin{array}{l}\text { Aspiration } \\
\text { pneumonia }\end{array}$ & 84.4 & 59.4 & 0.37 & 97.6 & 92.9 & 0.31 \\
\hline \multicolumn{7}{|l|}{ Geriatric: } \\
\hline $\begin{array}{l}\text { Eating/Swallowing } \\
\text { function }\end{array}$ & 75.0 & 87.5 & 0.25 & 95.2 & 95.2 & 1.0 \\
\hline Eating function & 87.7 & 93.8 & 0.24 & 97.6 & 95.2 & 0.56 \\
\hline Swallowing & 78.1 & 93.8 & $0.042^{*}$ & 95.2 & 95.2 & 1.0 \\
\hline $\begin{array}{l}\text { function } \\
\text { Walking function }\end{array}$ & 43.8 & 500 & $\cap \cap \cap 1$ ** & 600 & 786 & \\
\hline Nutritional & 75.0 & 84.4 & $0.001 * 2 *$ & $\begin{array}{l}09.0 \\
100\end{array}$ & $\begin{array}{l}70.0 \\
100\end{array}$ & $\begin{array}{l}0.32 \\
\mathrm{NE}\end{array}$ \\
\hline condition & & & & & & \\
\hline Cognitive function & 62.5 & 81.3 & $0.019 *$ & 97.6 & 100 & 0.31 \\
\hline $\begin{array}{l}\text { Feelings } \\
\text { happiness: } \\
\text { Ouality of life }\end{array}$ & 84.4 & 90.6 & 0.41 & 100 & 100 & $\mathrm{NE}$ \\
\hline $\begin{array}{ll}\text { Healthy } & \text { life } \\
\text { expectancy } & \end{array}$ & 90.6 & 84.4 & 0.057 & 100 & 97.6 & 0.31 \\
\hline
\end{tabular}

An awareness survey of dental students before and after clinical training was performed. A total of 42 dental students were recruited before clinical training, and 32 dental students responded to the survey. A total of 42 dental students were recruited after clinical training, and 42 dental students responded to the survey. Significant differences between periodontal and prosthetic treatment were examined using Fisher's exact test. *, $\mathrm{P}<0.05 ; * *, \mathrm{P}<0.01$. NE, not examined. The boldface indicates the "significantly higher" results. 